A Fortaleza de

\section{São José de Macapá:}

nos rastros das

memórias das

prisões e torturas

(1964-1973)

\author{
Maura Leal da Silva [*]
}

[*] Professsora adjunta do Curso de História, Universidade Federal do Amapá (Unifap), campus Marco Zero, Macapá

(AP), Brasil. mauraleal.ap@gmail.com

ORCID: https://orcid.org/0000-0003-4373-7507

\section{Janaína Valéria Pinto Camilo [**]}

$\left[{ }^{* *}\right][$ Professora adjunta do Curso de História do Centro de Formação de Professores da Unidade Acadêmica de Ciências Sociais da Universidade Federal de Campina Grande (UFCG). Cajazeiras (PB), Brasil.

janainavpcamilo@gmail.com

ORCID: https://orcid.org/0000-0002-4553-7341

Artigo recebido em 10 de setembro de 2020 e aprovado para publicação em 11 de janeiro de 2021.
Resumo: Lugares de memória têm se institucionalizado como locais marcados pela violência do Estado e pelo ocultamento devido a essa utilização. Assim, este artigo aborda o uso da Fortaleza de São José de Macapá - construção militar erguida no século XVIII na atual cidade de Macapá, capital do Amapá - como um dos lugares de memória da ditadura [brasileira]. Após um longo período de abandono, entre o século XIX até a criação do Território Federal do Amapá, em 1943, essa fortaleza recebeu as primeiras intervenções arquitetônicas para abrigar a Guarda Territorial e, em 1964, foi utilizada como local de prisões políticas. Após a coleta de testemunhos das vítimas e familiares da ditadura pela Comissão Estadual da Verdade do Amapá, passou-se a reivindicar para o "forte de Macapá" o uso institucional de um dos lugares de memória daquele período. Esses testemunhos vão de encontro à memória oficial, evidenciando aspectos pouco conhecidos da história desse lugar.

Palavras-chave: Fortaleza de São José de Macapá; Comissão da Verdade; Lugares de Memória.

\section{The Fortress of São José de Macapá: on the traces of prisons and tortures memories (1964-1973)}

Abstract: Places of memory have been institutionalized as places marked by the State violence and by its concealment due to such occurrence. Thus, this article discusses the use of the Fortress of São José de Macapá - military building from the 18th century in Macapá, capital of Amapá State - as one of the places of memory from the Brazilian dictatorship. After a long period of abandonment, between the 19th century and the establishment of the Federal Territory of Amapá, in 1943, the fortress suffered the first architectural interventions to house the Territorial Guard and, in 1964, it was used as a location aimed at political prisoners. After the gathering of testimonies of dictatorship victims and families by the Truth Comission of Amapá, it was demanded to the fortress of Macapá the institutional use of one of the memory places from that period. These testimonies meet the official memory, highlighting little known historical aspects of that place.

Keywords: Fortress of São José de Macapá; Truth Commission; Places of Memory. 


\begin{abstract}
A história de Macapá é muito furada, ninguém tem dados concretos. O governo queimava tudo. Nós ficamos 'sem história'. Muitas vezes eu vou aqui na fortaleza, e vejo que não era assim, porque eu vivi aqui. Eu fui criado nessa fortaleza. Quando papai foi preso lá, eu que levava café pra ele. Quando ele foi preso, encapuzaram ele, amararam ele com arame farpado (Raimundo Tupã dos Santos Pereira, ${ }^{1} 17$ mar. 2013, p. 3).
\end{abstract}

A narrativa que inicia este artigo faz parte de um conjunto de 38 testemunhos produzidos pela Comissão Estadual da Verdade do Amapá (CEV-AP), entre os anos de 2013 e 2017.² Assim como no testemunho acima, a Fortaleza de São José de Macapá (FSJM) é citada por quase todos os depoentes como um dos lugares de presos políticos durante a ditadura civil-militar em território amapaense. Não é possível precisar quantas pessoas foram encarceradas por razões políticas nesse forte no referido período (não foram localizados arquivos com esses dados), mas, através dos rastros de memórias de homens e mulheres que tiveram suas vidas afetadas por essas prisões arbitrárias, é possível afirmar que, desde o golpe civil-militar até 1973, ano da “Operação Engasga” em Macapá (acontecimento citado por esses testemunhos como o ápice das prisões), tais aprisionamentos ocorreram de forma frequente.

Este artigo é a materialização das nossas memórias, aqui traduzidas para um fazer histórico. Nascemos em Macapá, quando a cidade era a sede do então Território Federal do Amapá, transformado em estado em 1988. Durante nossa infância, a Fortaleza de São José de Macapá sempre representou um lugar de fascínio, pela grandiosidade de suas muralhas e em razão das histórias que ouvíamos sobre o lugar onde pessoas foram escravizadas e torturadas. Essa primeira memória, conforme Paul Ricoeur, é denominada "rastros psíquicos", que são, por exemplo, lembranças da infância "que não foram definitivamente apagadas, mas apenas tornadas inacessíveis, indisponíveis, o que nos leva a dizer que esquecemos menos do que acreditamos ou que tememos" (Ricouer, 2007, p. 426). Nesse sentido, a felicidade de lembrar diz respeito à ação de retirar do esquecimento fragmentos do passado.

De alguma forma, as lembranças da infância despertaram nossa curiosidade e influíram na decisão de cursar a graduação em história. Com isso, aquele amontoado de pedras passou, como nas palavras de Jacques Le Goff (1984), de "monumento" a “documento", e nossos

\footnotetext{
1 Tupã é filho de Raimundo Pereira Duarte, o "Periquito". Seu pai foi várias vezes preso sob a acusação de comunismo, por ter sido um dos fundadores e presidente do Sindicato dos Estivadores no Amapá.

2 Todo o acervo oral e documental produzido pela CEV-AP está sob a guarda temporária do Centro de Memória, Documentação Histórica e Arquivo da Universidade Federal do Amapá.
} 
questionamentos foram transformados em problemas a serem investigados, traduzidos em dois campos de pesquisas, distintos em suas temporalidades mas entrelaçados em suas inquietações. Uma das autoras seguiu o rastro da Amazônia Colonial na busca por compreender os motivos que levaram Portugal a construir essa fortificação no litoral amazônico. A outra, pesquisadora do Brasil República, deparou-se, quando integrante da Comissão Estadual da Verdade do Amapá, com testemunhos marcados pelos horrores da ditadura, que traziam à tona as memórias de quem vivenciou momentos de terror e dor. Nas duas pesquisas, o passado violento da Fortaleza de São José de Macapá se entrelaça aos traumas deixados tanto pela escravidão quanto pela ditadura.

Compreendemos que é difícil dissociar esse forte de seu significado histórico e políticosob o qual a cidade de Macapá foi sendo erguida ao longo desses mais de dois séculos, o que nos faz lembrar Michael Pollak (1989), na introdução do seu conhecidoensaio "Memória, esquecimento e silêncio". Ao citar Maurice Halbwachs e Pierre Nora, o autor enfatiza a força que os diferentes pontos de referência, como exemplo, os monumentos arquitetônicos que nos acompanham ao longo da vida, possuem na estruturação da nossa memória, inserindo-a na coletividade à qual pertencemos. Halbwachs é considerado o primeiro autor a formular de forma mais elaborada a compreensão da dimensão coletiva da memória, mas foi Pollak que chamou atenção para o caráter destruidor, uniformizador e opressor de uma memória coletiva nacional em contraposição a uma memória subalterna.

Esse aspecto do forte como monumento arquitetônico que documenta historicamente a cidade foi muito enfatizado nos testemunhos coletados pela Comissão Estadual da Verdade do Amapá. Porém, destaca-se a força que esses testemunhos possuem em oposição a uma memória oficial sobre a Fortaleza de São José de Macapá, trazendo da obscuridade aspectos pouco conhecidos da história desse lugar, conforme nos diz Pollak, e reabilitando da periferia e da clandestinidade memórias proibidas e marginalizadas pelo discurso hegemônico. Esse movimento de trazer das profundezas do silêncio essas memórias subalternas "consiste [...] muito mais na irrupção de ressentimentos acumulados no tempo e de uma memória da dominação e de sofrimentos que jamais puderam se exprimir publicamente" (Pollak, 1989, p. 5).

Portanto, nossa principal pretensão neste artigo é refletir sobre o uso desse forte (construção militar portuguesa do século XVIII e que hoje é considerado, pelo Instituto do Patrimônio Histórico e Artístico Nacional - Iphan, como Patrimônio Histórico Nacional) ${ }^{3}$ como lugar onde ocorreram prisões e torturas durante o regime ditatorial brasileiro, entre os anos de 1964 e 1973. Esse marco de nove anos foi pensado em razão de os testemunhos da CEV-AP abrangerem as prisões de homens e mulheres encarcerados nesse forte durante

${ }^{3}$ Conforme a Lista dos Bens Tombados e Processos em Andamento, atualizada em 25 de novembro de 2019. Disponível em: <http://portal.iphan.gov.br/pagina/detalhes/126>. Acesso em: 27 ago. 2020. 
esse período, o que não quer dizer que não tenham ocorrido prisões e torturas posteriores a 1973 nessa fortaleza.

Em Macapá, assim como em várias outras cidades do Brasil, diversos lugares foram utilizados como centros de prisões e torturas de presos políticos durante a ditadura civil-militar. A Delegacia do Bairro do Trem, as celas do Palácio do Setentrião e da Polícia Federal, o Quartel do Exército, a Prisão do Beirol, a Central de Polícia, a Delegacia de Investigação e Captura (DIC) e a Fortaleza de São José de Macapá foram espaços identificados pela CEV-AP como esses locais. Porém, o fato de o "forte de Macapá" ter sido citado por esses testemunhos como o principal lugar de cárcere de presos políticos levou-nos a pensá-lo como um dos lugares de memória da ditadura brasileira, conforme a expressão cunhada pelo historiador francês Pierre Nora (1993).

Segundo esse autor, os lugares de memória são monumentos e documentos da história nacional com uma tripla função: material, funcional e simbólica, em que a memória coletiva se ancora, se expressa e atua como espaço revelador dos conflitos e de disputas que envolvem o constante processo de construção da memória. Esses lugares possuem, ainda, um papel narrativo de consolidação e de totalização dessas memórias, reunindo elementos característicos de um grupo, conferindo-lhe sentido e unificando-o, configurando, com isso, uma rede articulada de identidades diferentes, ou seja, "uma organização inconsciente da memória coletiva que nos cabe tornar consciente de si mesma" (Nora, 1993, p. 13).

Em suma, essa discussão compreende que os lugares de memória são testemunhos materiais do passado e, como tais, funcionam como elo entre as inquietações do presente e um passado que ainda não foi devidamente esclarecido. Com base nos resultados apresentados pelo Relatório final e nos testemunhos da Comissão Estadual da Verdade do Amapá, o presente artigo objetiva analisar os acontecimentos que tiveram lugar na Fortaleza de São José de Macapá, que lhe atribuem o caráter de local de prisões e torturas durante a ditadura civil-militar brasileira e, assim, ajudar no processo de reconhecimento dos lugares de memória da ditadura, através da publicização dos fatos encobertos pela violência perpetrada pelo Estado durante os anos ditatoriais no Brasil.

\section{A Fortaleza de São José de Macapá como lugar de memória da ditadura}

Nos anos que seguiram ao fim da colonização, do Império, até a criação do Território Federal do Amapá, ${ }^{4}$ em 1943, a Fortaleza de São José de Macapá, inaugurada em 1782, sem

${ }^{4}$ O nascimento do Amapá, um dos mais jovens estados brasileiros, está inserido na experiência dos Territórios Federais. Sua criação ocorreu por meio do decreto-lei n. 5.812, de 13 de setembro de 1943, que também criou os Territórios Federais 
que a sua construção tivesse sido finalizada, ficou abandonada e foi tomada pelo mato. Foi só após esse período que passou a ser vista como patrimônio histórico da região e recebeu as primeiras intervenções arquitetônicas. ${ }^{5}$ À época, suas dependências passaram a ser utilizadas para sediar órgãos da administração pública do recém-instalado governo.

Em 1964, quando ocorreu o golpe civil-militar no Brasil, a FSJM alojava, desde 1944, a Guarda Territorial, ${ }^{6}$ de caráter civil, criada com a finalidade de exercer o policiamento e a segurança pública dos Territórios Federais. Conforme as memórias escritas pelo jornalista amapaense Hélio Pennafort (16 nov. 1997), os calabouços da FSJM já eram utilizados para prender "delinquentes" e "supostos inimigos" dos governadores. Porém, segundo Adamor de Oliveira, um dos depoentes na CEV-AP, após 1964 o forte de Macapá passou a sediar somente a Guarda Territorial, com um efetivo de 120 homens, e a Corporação do Tiro de Guerra 130, que era parte do Exército Brasileiro, passando a servir "como local de presos políticos, de triste memória" (Oliveira, 2013, p. 163). De acordo com outro testemunho, de J. L. P.: "quando terminou a Guarda, em 1975, o efetivo era de 478, 470 guardas" (P., J. L., CEV-AP, 12 nov. 2014, p. 5).

Até a criação da Polícia Militar, em 1975, o policiamento do Território Federal do Amapá foi praticamente exercido pela Guarda Territorial, a quem coube a tarefa da repressão às infrações de rotina, e pelo Departamento de Ordem Política e Social (Dops), apoiado pela Polícia Federal, cuja responsabilidade incidia sobre as infrações de natureza política. Entretanto, a repressão no Amapá, assim como no restante do país, era praticada através de um complexo Sistema de Segurança Interna (Sissegin), que articulava todas as forças policiais e militares, como o relatório da CEV-AP descreveu:

[...] o caminho percorrido pelos presos políticos no Amapá de certo modo atesta a articulação entre órgãos militares e civis na efetivação da repressão: primeiro eles iam para o quartel do Exército, para a Central de Polícia ou para a Polícia Federal e daí diretamente para a Fortaleza de São José de Macapá, e alguns eram enviados em aviões das Forças Armadas para encarceramento em Belém-PA (Amapá, 2017, p. 23).

do Rio Branco, do Guaporé, de Ponta Porã e de Iguaçu de partes desmembradas, respectivamente, dos estados do Pará, Amazonas, Mato Grosso, Paraná e Santa Catarina. Sua emancipação política só ocorreu após um período de 45 anos (Silva, 2017).

${ }^{5}$ Essas primeiras intervenções estiveram pouco comprometidas com as premissas das cartas patrimoniais que orientavam os procedimentos para preservação e conservação de patrimônios materiais, como a Carta de Atenas, de 1931, e a Carta de Veneza, de 1964, conhecida como a Carta Internacional do Restauro exatamente por orientar e difundir técnicas e materiais adequados à restauração dos patrimônios históricos.

${ }^{6}$ Decreto-lei n. 5.839, de 21 de setembro de 1943. Dispõe sobre a administração dos Territórios Federais do Amapá, do Rio Branco, do Guaporé, de Ponta Porã e do Iguaçu. Normatiza, entre outras coisas, a criação da Guarda Territorial nos respectivos Territórios Federais. 
Figura 1 - Entrada principal da Fortaleza de Macapá, anos 1960 (Amapá, 2017, p. 65).

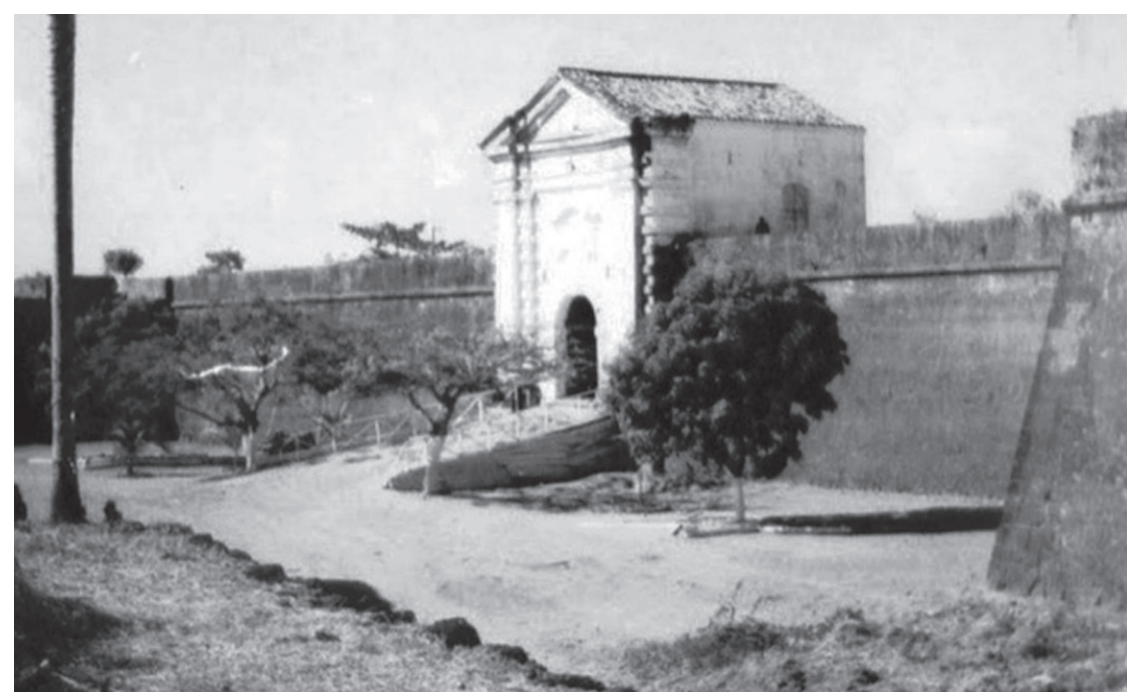

A descrição acima atesta o funcionamento em rede do sistema de repressão no Brasil que, no caso do Amapá, subordinava-se à $8^{a}$ Região Militar, sediada em Belém, no Pará. Dentro do território amapaense, no itinerário percorrido pelos presos políticos, a FSJM era praticamente destino certo. Contudo, ainda há um longo caminho a ser percorrido para que locais como o forte de Macapá, espalhados pelo Brasil, possam ser reconhecidos como lugares onde ocorreram graves violações aos direitos das pessoas, como lentes de um passado violento que não deve se repetir. Conforme Nora:

Os lugares de memória nascem e vivem do sentimento [de] que não há memória espontânea, que é preciso criar arquivos, que é preciso manter aniversários, organizar celebrações, pronunciar elogios fúnebres, notariar atas, porque essas operações não são naturais [...]. Mas, se o que eles defendem não estivesse ameaçado, não se teria, tampouco, a necessidade de construí-los (Nora, 1993, p. 13).

O surgimento de lugares de memória não ocorreu por acaso. Faz parte de um amplo movimento global do que se compreende por justiça transicional, ${ }^{7}$ sobretudo a partir do momento em que acontecimentos silenciados institucionalmente passaram a ser problematizados por narrativas de homens e mulheres que vivenciaram experiências vinculadas a

${ }^{7}$ Ver Tosi et al. (2014) 
determinados espaços onde ocorreu prática de violência por parte de instituições públicas. Tais testemunhos foram fundamentais para que as evidências viessem à tona e o silêncio se quebrasse em um trabalho de reconhecimento dos crimes cometidos nesses lugares. Esse movimento de identificação no Brasil, com registros também nos demais países do Cone Sul que viveram experiências ditatoriais, acompanha, portanto, uma tendência mundial em que se observa a criação de instituições museais que adotam as causas locais, com relação aos direitos humanos, como questão principal (Hoffman; Frota, 2019). Geralmente esses lugares foram utilizados no passado recente como centros de prisões e torturas durante esses regimes.

No Brasil, a identificação de locais que lidam com as memórias da repressão e resistência associadas à violência de Estado é geralmente decorrente das lutas encampadas pela sociedade civil, majoritariamente, por familiares de mortos e de desaparecidos políticos e por ex-presos políticos, de maneira isolada ou em organizações civis e comissões. Tanto a criação pelo Estado brasileiro da Comissão Especial sobre os Mortos e Desaparecidos Políticos, em 1995, como da Comissão de Anistia, em 2002, é fruto de antigas pressões da sociedade civil organizada, que realizou investigações paralelas sistematizadas em dois importantes compêndios documentais: os dossiês dos mortos e desaparecidos políticos (edições 1984, 1996 e 2008) e os relatórios do projeto "Brasil nunca mais". ${ }^{8}$

A longa luta pela instituição de políticas de memória reflete historicamente o entendimento de que o Estado deve promover políticas de reconhecimento dos abusos e crimes cometidos, como também gerar mecanismos de prevenção para que a sociedade não se torne mais refém de práticas cerceadoras das liberdades. Quanto mais os crimes cometidos durante os regimes de exceção cheguem ao conhecimento público, mais perto estaremos de evitar a repetição dos erros do passado e, consequentemente, da construção de uma sociedade alicerçada na democracia:

[...] é uma tentativa para esconjurar ou desafiar a reversibilidade dos acontecimentos históricos, colocando (pelo que é humanamente possível) um ponto firme, uma virada de página, um ponto de não retorno, uma cláusula pétrea no pacto social que funda um Estado Democrático de Direito (Tosi et al., 2014, p. 45).

Dos países do Cone Sul que viveram regimes ditatoriais, o Brasil foi o último a instituir um mecanismo oficialmente reconhecido para investigar, esclarecer e reconhecer formalmente os crimes da época da ditadura. A lei n. 12.528, que criou a Comissão Nacional da Verdade (CNV), data de 18 de novembro de 2011, quase 30 anos após a promulgação da Lei de Anistia de 1979. É importante lembrar, conforme Caroline Bauer (2017), que a instituição da CNV foi marcada

${ }^{8}$ Ver <http://www.memoriasreveladas.gov.br/>. 
por paradoxos, ambiguidades e disputas políticas que refletiram nos resultados apresentados em seu Relatório final, entregue à sociedade brasileira em 2014 (Brasil, 2014).

A formação da Comissão Estadual da Verdade do Amapá foi impulsionada pelo contexto nacional que o Brasil vivia, e objetivou, assim como as demais comissões que foram criadas no período, oferecer subsídios à CNV e contribuir para a elucidação das violações aos direitos humanos cometidos no então Território Federal do Amapá durante a ditadura civil-militar. Sua criação, em junho de 2013, se deu por iniciativa do governo do estado do Amapá, mas sua conclusão, em junho de 2017, só foi possível pelo protagonismo dos docentes e discentes do curso de história da Universidade Federal do Amapá9 e dos demais membros (uma secretária executiva, um professor de história da educação básica do estado e um servidor comissionado).

Assim como a CNV, a CEV-AP sofreu ingerência de disputas políticas em torno de sua criação, atuação e permanência. À época de sua origem, estava à sua frente o executivo Camilo Capiberibe, filho de ex-presos políticos que nasceu no Chile durante o exílio de seus pais, João Capiberibe (Capi) e Janete Capiberibe. ${ }^{10}$ Segundo o então governador:

A existência dessa comissão é fruto da militância daqueles que lutaram contra a ditadura, foram presos, torturados, expulsos deste país. Eu nasci fora do Brasil [...], de certa maneira me foi roubado o direito (como a minha mãe é amapaense, meu pai é marajoara) de ser amazônida. [...] Não sou chileno. Eu sou brasileiro. Mas esse direito me foi roubado pela ditadura e toda uma geração (Capiberibe, 28 mar. 2014).

No início de 2015, com a alternância do poder, a CEV-AP teve suas atividades paralisadas e só retornou em maio daquele ano após pressões de seus membros pela sua continuidade, mas com apoio e equipe de trabalho reduzidos. Diferente da CNV, a comissão do Amapá não se originou da pressão local da sociedade civil organizada, mas o fato de ter sido a primeira e uma das poucas Comissões da Verdade na Amazônia a ser criada e a encerrar suas atividades indica sua importância para compreensão dos desdobramentos da ditadura bra-

\footnotetext{
${ }^{9}$ De acordo com Mônica Tenaglia e Georgete Medleg Rodrigues, que analisaram os relatórios finais de várias comissões da verdade publicizados até a data da pesquisa, as dificuldades enfrentadas pela CEV-AP foram enormes e a Unifap acabou se tornando uma parceria fundamental para a realização dos trabalhos: "para enfrentar as dificuldades resultantes da ausência de gestão dos arquivos utilizados, a comissão firmou uma parceria com a Universidade Federal do Amapá (Unifap), que disponibilizou estagiários do curso de história para desenvolver as atividades de transcrição das oitivas, organização do acervo documental e pesquisa sobre dados biográficos" (Tenaglia; Rodrigues, 2018, p.290).

10 Capi e Janete Capiberibe, integrantes da Ação Libertadora Nacional (ALN), foram presos em 1970, em Belém. No ano seguinte, seguem para o exílio na Bolívia, Peru. Chile, de onde saem em 1973, após o golpe militar também nesse último país (Capiberibe, 2013).
} 
sileira nessa região, como também nos ajuda a compreender sua importância para a identificação de lugares de memória da ditadura no extremo norte do Brasil.

Não pretendemos nos alongar nessa questão (pois não é o objetivo deste artigo), mas, como bem analisado por Bauer (2017), evidenciar esse processo histórico turbulento que levou à instalação da CNV e das demais comissões da verdade ajuda a compreender que tais instituições são políticas de memória elaboradas pelo Estado no âmbito do processo de Justiça de Transição, com a finalidade de gerir memórias sobre a história recente brasileira, fazendo usos políticos do passado que podem tanto se desdobrar em iniciativas de reconhecimento e reparação, como em perpetuação de esquecimentos e silenciamentos induzidos, da mesma forma que reforçam a "relação entre a história, memória e esquecimento" (Bauer, 2017, p. 112).

Sobre essa relação sempre tão desafiadora entre a história, memória e esquecimento, Pollak nos faz refletir sobre o significado desse "gerenciamento" de memórias em uma sociedade na qual se impôs oficialmente o silenciamento dos crimes do passado (com gesto forçado de apagar, de ignorar, de fazer como se não tivessem ocorrido). Segundo esse autor: "o longo silêncio sobre o passado, longe de conduzir ao esquecimento, é a resistência que uma sociedade civil impotente opõe ao excesso de discursos oficiais" (Pollak, 1989, p. 5). Portanto, por mais que se tente silenciar essas memórias subalternas, em momentos de crise elas afloram e entram em disputas: "reivindicações múltiplas e dificilmente previsíveis se acoplam a essa disputa da memória" (Pollak, 1989, p. 5). No Brasil, onde se tentou forjar uma cultura do esquecimento dos crimes cometidos no período de 1964 a 1985, a negação das falas das vítimas e de seus familiares se impôs de forma muito violenta e muitos fatos desse passado ficaram obscurecidos, mas jamais esquecidos. Nesse processo transacional, como afirma Edson Teles (2018, p. 46): "foram raros os momentos em que as vítimas puderam construir narrativas sobre a violência sofrida e o modo como compreendiam a história do país".

O que nos chamou atenção nesse movimento tardio de proliferações de comissões da verdade, como o que se registrou no Brasil, é que os testemunhos colhidos pela CEV-AP trazem à tona memórias proibidas, que se opõem à força avassaladora da mais poderosa das memórias coletivas, a memória nacional, e contribuem para o conhecimento de um passado da história recente do Brasil no extremo norte do país até o momento pouquíssimo conhecido.

Foi só recentemente, a partir dos testemunhos produzidos pela $\mathrm{CEV}$-AP, que se passou a reivindicar para a FSJM o reconhecimento institucional como um dos lugares de memória da ditadura brasileira. Na literatura especializada, localizamos pela primeira vez uma menção ao forte de Macapá como lugar de prisões e torturas da ditadura em 2001, na dissertação O regime ditatorial militar no Amapá: terror, resistência e subordinação, do historiador Dorival San- 
tos. Nela, o autor, a partir de entrevistas com ex-presos políticos, faz referência à fortaleza como "símbolo de ícone do medo" do período."

Fernando Canto, em Vertentes discursivas da Fortaleza de São José de Macapá, de 2014, chamou atenção para o fato de que a ditadura no Amapá também se valeu da carga imaginária que o forte sempre exerceu sobre a população local para disseminar, especialmente entre os estudantes, as ideologias favoráveis ao regime em desfiles cívicos no seu entorno, enquanto se praticava nos porões da fortaleza a violência de Estado. Porém, foi só recentemente, em outra publicação, "Literatura e memória: a Fortaleza de São José de Macapá no contexto da ditadura militar em Macapá (1964-1973)”, de 2018, quando já havia dado seu testemunho a CEV-AP, que Fernando Canto, ao analisar uma literatura produzida por jornalistas e escritores que vivenciaram os anos ditatoriais no Amapá, se refere à FSJM como "depósito de presos políticos" e como lugar de memória da ditadura (Canto, Silva, 2018).

Nesse artigo, publicado em conjunto com sua orientadora de doutorado Isabelle da Silva, Canto, como amapaense e como personagem que vivenciou a ditadura, insere no texto narrativas de vítimas da ditadura no Amapá já falecidas. Pessoas que foram encarceradas na FSJM e que não puderam ser entrevistadas pela CEV-AP como o jornalista Jorge Hernani, que morreu em 2006. Hernani deixou manuscritos com amigos, entre eles Canto, de uma memória que estava escrevendo, sobre a época em que foi preso pela Operação Engasga. ${ }^{12}$ Na "Engasga" (como ficou conhecida popularmente a operação militar de 1973) foram presas em Macapá aproximadamente quarenta pessoas, acusadas de subversão e comunismo. Segundo Hernani:

A fortaleza, que foi tombada pelo Instituto do Patrimônio Histórico Artístico Nacional e que consumiu a mão de obra escrava do negro e do índio durante 18 anos de trabalhos, nunca foi usada em combate. Para essa estrutura rudimentar, mas de grande segurança, foram levados os presos mais 'perigosos' do engasga-engasga. Bastaram poucas horas desde que tudo começou para que a polícia desse início a uma verdadeira 'operação caça às bruxas'. A repressão do Território já tinha a situação sob controle, ou seja, sabia

\footnotetext{
${ }^{11}$ A publicação dessa dissertação só ocorreria dezesseis anos após sua escrita, em 2017, sob o título Entre a tortura e Matinta Pereira: uma abordagem cultural da ditadura militar no Amapá, também impulsionada pelos trabalhos da CEV-AP, da qual o autor fez parte, como seu último presidente.

${ }^{12}$ A Operação Engasga foi uma ação de terror de Estado peculiar da realidade amapaense, por ter se valido do imaginário social para gerar um medo generalizado entre a população. A retórica da existência do perigo comunista, advinda da ação de elementos vis e perniciosos, conhecidos como "engasgadores" de mulheres, acabou servindo para justificar as ações militares e policiais na região. Mesmo com o pânico disseminado, nenhuma mulher chegou a ser assassinada ou gravemente ferida nesses ataques. Há relatos de vítimas que tiveram pequenos ferimentos no pescoço, em razão de uma suposta luva coberta por uma lixa grossa que era usada pelo agressor ou agressores, muito embora não tenha sido localizado na época e nem no presente nenhum registro de ocorrências ou inquéritos policiais que comprovem a existência dos engasgadores (Amapá, 2017).
} 
dos nomes, endereços e locais de trabalhos dos 'indivíduos de esquerda' que deveriam ser presos sob a acusação de serem os homens que estavam aterrorizando a cidade. As prisões se sucederam rapidamente mesmo porque nenhum dos visados pela polícia tentou se esconder ou fugir de Macapá, por mais que aquela boataria fosse longe demais. Aos poucos eles foram recolhidos e agrupados na fortaleza. A cada passo que davam sobre as pedras centenárias do forte, consumava-se uma sentença sem o direito de defesa. Estavam incomunicáveis, alguém da família que tentasse saber de notícias corria o risco de também ser preso, de ficar isolado na fortaleza sem nenhuma culpa comprovada (Hernani, 2004 citado em Canto, Silva, 2018, p. 316).

Para uma cidade pacata com aproximadamente 27 mil habitantes como Macapá, onde as relações ainda se estabeleciam através de hábitos de vizinhança e camaradagem (Santos, 2001), a repercussão e a quantidade de pessoas encarceradas durante essa operação (a maioria na FSJM) são relatadas por quase todos os testemunhos da CEV-AP como momento em que a violência do Estado atingiu seu ápice no Amapá, confirmando a Fortaleza de São José de Macapá como principal palco de prisões e torturas do regime ditatorial na região.

\section{Os testemunhos de prisões e de torturas na Fortaleza de São José de Macapá}

Em seu Relatório final, entregue à sociedade amapaense em 31 de março de 2017, a Comissão Estadual da Verdade do Amapá destacou a existência de dois locais que foram os principais centros de prisão em território amapaense durante a ditadura. Os suspeitos de envolvimento com comunismo e subversão ou aqueles que simplesmente discordavam dos rumos políticos eram encarcerados e, em muitos casos, submetidos a torturas físicas e psicológicas nestes lugares, a saber: a Delegacia de Investigação e Captura (DIC), localizada nos fundos do prédio onde atualmente funciona o Museu Histórico Joaquim Caetano da Silva (e que teve já variadas funções, entre elas: Intendência de Macapá, Conselho de Intendência, Câmara de Vereadores e Tribunal do Júri) e as dependências da Fortaleza de São José de Macapá. No mesmo relatório, a CEV-AP recomendou ao poder público que desse prosseguimento aos trabalhos de pesquisa e identificação dos sítios de memória, instalando neles placas que registrem e homenageiem as vítimas das violações dos direitos humanos durante a ditadura, com destaque para a instalação de um Memorial da Verdade na Fortaleza São José de Macapá, o que até o presente não se concretizou (Amapá, 2017).

Embora a região Norte tenha sido afetada, assim como as demais regiões brasileiras, pela ditadura civil-militar, as pesquisas e políticas transicionais se concentraram quase que exclusivamente no eixo Sul-Sudeste. Pouco se sabe sobre como a ditadura atuou em estados 
brasileiros localizados no norte do país que viviam sob o regime de territórios federais. Existe mais uma agravante: esse campo de pesquisa, no Amapá, foi construído sob estigma negacionista o qual, conforme Caroline Bauer (2020), vem ganhando força no Brasil na última década, alterando significativamente os sentidos e os usos políticos do passado da ditadura.

Nas pesquisas locais sobre esse período é quase consensual que Macapá não vivenciou a intensidade de prisões e torturas de cidades como São Paulo, Rio de Janeiro e Belo Horizonte. Essa tendência, de se compreender a ditadura em nível local como mais branda com relação à nacional, contribui também para uma visão amenizadora do período. Soma-se a isso vasta historiografia ${ }^{13}$ que solidifica a argumentação de que a ditadura brasileira foi branda quando comparada à experiência de outros países do Cone Sul, como a Argentina. Em nível local, a comparação se estabelece como forma de abrandar ainda mais a percepção da ditadura e até mesmo de negar sua existência, fato que acaba reforçando no imaginário social amapaense, nesse caso, a defesa de que a ditadura nem sequer existiu nessa região, a qual é acentuada pelo argumento de que se não houve mortes e desaparecimentos não houve, portanto, ditadura. No depoimento de João Cardoso Neto, ex-agente de polícia que chegou a trabalhar como escrivão substituto no Dops em Macapá, essa forma de enxergar a ditadura local como mais branda do que a nacional é explícita:

Pois é, gente, eu sempre digo que, de todo Brasil, onde a revolução menos operou foi no Amapá. Operou assim em maneira de rusticidade, de ignorância, de estupidez, porque o que se viu aí pra fora... Rio de Janeiro. Esse problema do Araguaia que viram desaparecer com as pessoas, pau de arara, choque elétrico de Belém pra lá. Eu garanto pra vocês que aqui não (Cardoso Neto, 24 nov. 2014, p. 15).

O testemunho das vítimas que foram presas e torturadas no Amapá contraria a afirmação acima. Vejamos o depoimento de Josias Nogueira Hagem Cardoso, que foi sindicalista e integrante da Juventude Operária Católica. ${ }^{14}$

Tudo que eu declaro aqui o SNI já sabia, fomos [...] sumariados pelos militares, acusados de atividades subversivas e comunistas [...], culminando com a prisão de quase todos na Fortaleza de São José de Macapá e no porão do Museu Joaquim Caetano de Souza. Com o Ato Institucional n. 5 era assim: 'não fui com sua cara!' E por isso muitos

\footnotetext{
13 Ver Calil (2017).

${ }^{14}$ Em 1950, surgiram em Macapá os grupos de jovens da Igreja católica, são eles: Juventude Universitária Católica (JUC), Juventude Estudantil Católica (JEC) e Juventude Operária Católica (JOC). A princípio, definiam-se como “apolíticos”, com alguns segmentos chegando a seguir uma orientação pelo anticomunismo. Entretanto, em fins de 1950, a "esquerda cristã" já era maioria no JUC, JOC e no JEC, passando a intervir mais efetivamente no movimento estudantil secundarista. Com o golpe de 1964, muitos jovens desses grupos passaram a fazer parte da resistência contra a ditadura (Silva, 2017).
} 
foram demitidos. O AI-5 era tão violento que eles chegavam: 'não fui com a tua cara'. E estava condenado à morte. E pior que nenhum advogado queria nos defender [...]. Aqui no Amapá houve muita gente que foi torturada e depois não falou que foi torturada. A tortura foi feita sigilosamente e não ficava quase rastro de nada. Eles metiam a pessoa em um macacão de borracha e levavam aqui para o $\mathrm{km} 9 \mathrm{da}$ BR 156, que chamavam lá pau de arara, e espocavam o cara de porrada porque não deixavam marcas e ficava todo quebrado (Cardoso, 16 set. 2014, p. 16).

É fato que, até o presente, excetuados os casos dos soldados Cabral e Ovídio, ${ }^{15}$ mortos pelo "fogo amigo"16 na região da Guerrilha do Araguaia, por ocasião das operações militares contra militantes da resistência, não se tem registros de amapaenses ou habitantes do Amapá que tenham morrido ou desaparecido em consequência de ações de agentes da repressão, mas isso não quer dizer, como o relatório da CEV-AP concluiu, que não tenham ocorrido nessa região mortes e desaparecimentos nesse período - como se fosse possível mensurar em quantidade de mortos e desaparecidos a violência cometida por agentes da repressão e mascarar as gravidades de torturas e crimes que ecoam no presente nos números de violência do Estado, que tornam o Brasil um dos países com a polícia que mais mata no mundo. Nesse ranking, conforme dados do Anuário brasileiro de segurança pública, de 2019, o Amapá é, atualmente, o estado onde se registra a maior taxa de mortes por agentes da segurança pública.

Ainda que a realidade dos amapaenses apresente uma dinâmica diferente da nacional, não se pode ignorar que a ditadura ocorreu no Amapá como em qualquer outro lugar do território brasileiro e que talvez resida aí uma das principais razões que justifique que os estudos sobre o período necessitem ser alargados. O próprio trabalho realizado pela CEV-AP contraria a afirmação de que não existiu ditadura no Amapá, pois as conclusões atestam que as prisões ilegais e arbitrárias ${ }^{17}$ em território amapaense foram praticadas pelo regime militar desde primeiros dias do anúncio do golpe de 1964, atingindo seu ápice em 1973, com a Operação Engasga. Segundo Pennafort (16 nov. 1997), uma das principais medidas do

\footnotetext{
15 Conforme o testemunho de Raimundo José Rodrigues, que prestou serviço ao Exército brasileiro na Guerrilha do Araguaia, entre os anos de 1972-1973, as mortes de Ovídio e Cabral ocorreram por engano. Cabral foi confundido com um guerrilheiro e, por não proferir a senha da guarnição, seu companheiro,o cabo Nobre, acabou efetuando o disparo que o matou, em 1972. Já Ovídio teria sido alvejado, em 1973, por outro soldado quando retornava ao acampamento, após uma inspeção em busca de alimentos, em uma região com pouca luminosidade, de mata fechada e de difícil acesso. As circunstâncias da morte de Ovídio e Cabral não foram, à época, nem até o presente, devidamente esclarecidas pelo Exército (Amapá, 2017)

${ }^{16}$ Expressão eufêmica utilizada militarmente para descrever ataques de aliado a aliado.

17 Deve-se esclarecer que a CEV-AP acompanhou as orientações da CNV e considerou como grave violação de direitos humanos toda ou qualquer prisão ilegal e arbitrária nesse período, "seja porque já era assim considerada, como proibição imperativa para todos os Estados, seja porque foram tidas como uma espécie de porta de entrada do sistema repressivo do regime militar e um facilitador para a prática de outras graves violações" (Brasil, v. I, 2014, p. 278-279).
} 
governo militar no Amapá pós-64 foi a criação da Comissão de Investigação Sumária, que tinha por função descobrir e prender comunistas e subversivos. De imediato, os principais atingidos por essa medida foram os servidores públicos e políticos que manifestaram apoio ou compunham o bloco de oposição ao governo local (Santos, 2001).

Não é possível precisar em números quantas pessoas foram encarceradas na FSJM durante a ditadura sob a acusação de crime político. A própria comissão do Amapá não traz essa quantificação. Algumas suposições podem explicar esse silêncio. Além das pessoas ouvidas, existem muitas outras anônimas que não foram escutadas. Muitas já morreram ou não quiseram prestar depoimento. É preciso considerar também que o Estado ditatorial produziu silenciamentos e apagamentos de documentos que ajudariam no levantamento de informações sobre o que ocorreu nesse período. E o Amapá não fugiu a essa regra.

É bem verdade, paradoxalmente, conforme foi abordado no I Seminário Internacional Documentar a Ditadura, em junho de 2013, no Rio de Janeiro, que a recente ditadura brasileira nos deixou, como sombrio legado, o maior acervo documental entre suas congêneres no Cone Sul, reunido, desde 2007, no Centro de Referência das Lutas Políticas no Brasil e denominado "Memórias reveladas", sob a guarda do Arquivo Nacional..$^{18}$ Entretanto, além da abertura e da divulgação tardia desses arquivos, que só se concretizaram de fato com a promulgação da Lei de Acesso à Informação de 2012, um dos aspectos destacados pela CEV-AP que dificultou a realização de uma pesquisa mais aprofundada sobre o período consistiu, justamente, na ausência de um arquivo público disponível sobre a experiência amapaense, o que tornou o trabalho realizado pela CEV-AP ainda mais necessário, pois ela acabou cumprindo também o papel de resgate da história desse período.

O depoimento de Cláudio Nascimento, um dos presos políticos levado para a FSJM, narra a prática de queima de arquivos pelos agentes da ditadura. Ele, que foi submetido a torturas psicológicas durante trinta dias, sem poder ver sua família, afirmou que, enquanto esteve preso, presenciou a queima dos arquivos nesse período no Amapá: "lá na Fortaleza eu assisti à queima dos arquivos do governo [...]. Eles fizeram aquele monte e queimaram na nossa frente ali. Nós ficamos ali obrigados a assistir" (Nascimento, 28 ago. 2014, p. 4).

$\mathrm{Na}$ ausência de arquivos oficiais que documentassem as violências e atrocidades cometidas pelos agentes de repressão, a forma mais óbvia de recomposição da verdade foi promover e incentivar os testemunhos dos sobreviventes e de seus descendentes. Assim, o testemunho se transformou em peça jurídica e documento histórico. Ao se estimular o testemunho, reconstrói-se a verdade abafada pela ditadura e aquilo que era esquecimento se transforma em memória. Esse é o caso de comissões como a do Amapá, em que os testemunhos foram a marca das ações realizadas, ao também legitimarem um tipo específico de

${ }^{18}$ Ver <http://www.memoriasreveladas.gov.br/> 
depoimento oral, aquele que Márcio Seligmann-Silva (2003) chamou de literatura testemunhal. Para ele, esse tipo de testemunho, produto do terrorismo de Estado, é marcado pela necessidade de narrar o trauma e, ao mesmo tempo, pela dificuldade de narrá-lo.

Essas características apontadas por Seligmann-Silva (2003) para experiências provenientes de catástrofes também podem ser observadas nos relatos das vítimas da ditadura em território amapaense. Os depoimentos, colhidos em sua maioria de forma individual e reservada, foram cercados de grande emoção e, não raro, os homens e mulheres choraram ao reviver memórias de um passado recente doloroso. Nessas escutas marcadas pela violência política se exige sempre uma maior atenção, uma vez que expressam vivências e experiências que, na maioria das vezes, provocam o encontro com um passado traumático que se quer esquecer. Porém, testemunhar implica lembrar. E lembrar, nesse caso, tem o papel de ajudar a superar o trauma. Esse duplo aspecto fica evidente nos testemunhos que reportam as experiências marcadas pela dor, mas também pelo desejo de narrar o que aconteceu, conforme trecho a seguir:

Tive a infelicidade de participar desse momento tortuoso do país que até hoje existe. Nós fomos surpreendidos e achincalhados, presos, batidos, passados por todo um processo de humilhação sendo cidadãos trabalhadores. Eu estava trabalhando nesse dia. Cheguei aqui tinham invadido a minha casa. Fui para delegacia, ao chiqueiro que era a delegacia com um monte de bandido lá dentro e me mandaram direto para a Fortaleza. [...]. Eu apanhei menos que os outros porque não tinha espaço para me baterem. Sofri muito aquele constrangimento psicológico. Era muita gente. Na fortaleza tinha gente, não era brincadeira. Lá eu fiquei na fortaleza preso alguns dias e de lá fomos pra Belém amarrados com arame e passamos 31 dias, eu e mais oito companheiros na $5^{\underline{a}}$ Companhia de Guardas (Capiberibe, 21 mar. 2014, p. 1).

O que nos chamou atenção nas publicações de Fernando Canto sobre a FSJM (que citamos anteriormente) é como seus escritos dialogam com uma memória de quem também viveu essa experiência ditatorial. À época artista e estudante secundarista, Canto também foi um dos presos pela Operação Engasga, em 1973. Seu testemunho à CEV-AP, em 2016, foi marcado pela dificuldade de narrar esses acontecimentos vividos. Escrever talvez seja para ele uma forma menos dolorosa de encontrar um lugar para registrar essas lembranças.

[...] depois do 'engasga-engasga' [...] eu tive que ir embora daqui. Eu fui preso, toda hora a gente ia ser preso por qualquer motivo. A repressão era tão grande que a gente era marcado. A gente já sabia que se fizesse qualquer coisinha, sentasse sem carteira de identidade ia preso. Um negócio que realmente revoltou muita gente, traumatizou de alguma forma, né? Até hoje a gente sente isso (Canto, 2 set. 2016, p. 5). 
As narrativas trazidas por esses testemunhos nos remetem à memória coletiva de uma geração, a um discurso que cria identidade, não apenas para o entrevistado, mas, em muitos casos, para um grupo de pessoas que vivenciou essa época e seus acontecimentos (Araújo, 2013). Ademais, a riqueza de um depoimento é mostrar no presente como foram vividas e sentidas as experiências de um passado recente que insiste em não passar, mas que deve ser lembrado para que não se repita. Esse é o caso de testemunhos como os da CEV-AP, que não visam ao esquecimento, mas à narração precisa, mesmo que insuportável, dos acontecimentos e, sobre essa base comum de conhecimento, encontrar um lugar para essas memórias, pois, conforme Gagnebin (2010, p. 183): “convém muito mais tentar acolher essas lembranças indomáveis, encontrar um lugar para elas, tentar elaborá-las, em vez de se esgotar na vã luta contra elas".

\title{
Considerações finais
}

Fernando Canto (2014) escreve também sobre outra memória, mais feliz e mais suave, sobre a Fortaleza de São José de Macapá, bem diferente daquela testemunhada nos anos ditatoriais. Para ele, Macapá tem vários signos com significados amplos que poderiam ser citados como símbolos identitários da cidade, mas nenhum deles têm maior representatividade histórica e identitária do que a FSJM, sobretudo por localizar-se junto ao rio Amazonas, em um conjunto paisagístico que dá aos amapaenses a identificação amazônica do "transbordar de tanto amor", expressa na letra da música Jeito tucuju, ${ }^{19}$ que se tornou uma espécie de hino da cidade, a qual transcrevemos a seguir:

\author{
Quem nunca viu o Amazonas \\ Nunca irá entender a vida de um povo \\ De alma e cor brasileiras \\ Suas conquistas ribeiras \\ Seu ritmo novo \\ Não contará nossa história \\ Por não saber e por não fazer jus \\ Não curtirá nossas festas tucuju \\ Quem avistar o Amazonas nesse momento \\ E souber transbordar de tanto amor
}

\footnotetext{
19 Jeito tucuju é de autoria dos músicos amapaenses Joãozinho Gomes e Val Milhomem. Foi composta no início de 1990, na transição do Amapá de território federal para estado. Em 19 de setembro de 2017, o Projeto de Lei n. 0197/2017AL, de autoria do deputado estadual Furlan, transformou Jeito tucuju em hino cultural do Amapá. Ver Godinho (2019).
} 
Esse terá entendido o jeito de ser do povo daqui

Quem nunca viu o Amazonas

Jamais irá compreender a crença de um povo

Sua ciência caseira, a reza das benzedeiras

O dom milagroso.

Figura 2 - Fortaleza de São José de Macapá (Amapá Digital, 24 ago. 2020.

Disponível em: <http://www.amapadigital.net/images/photos/img_ galeria/fortaleza\%20(1).jpg>. Acesso em: 24 ago. 2020).

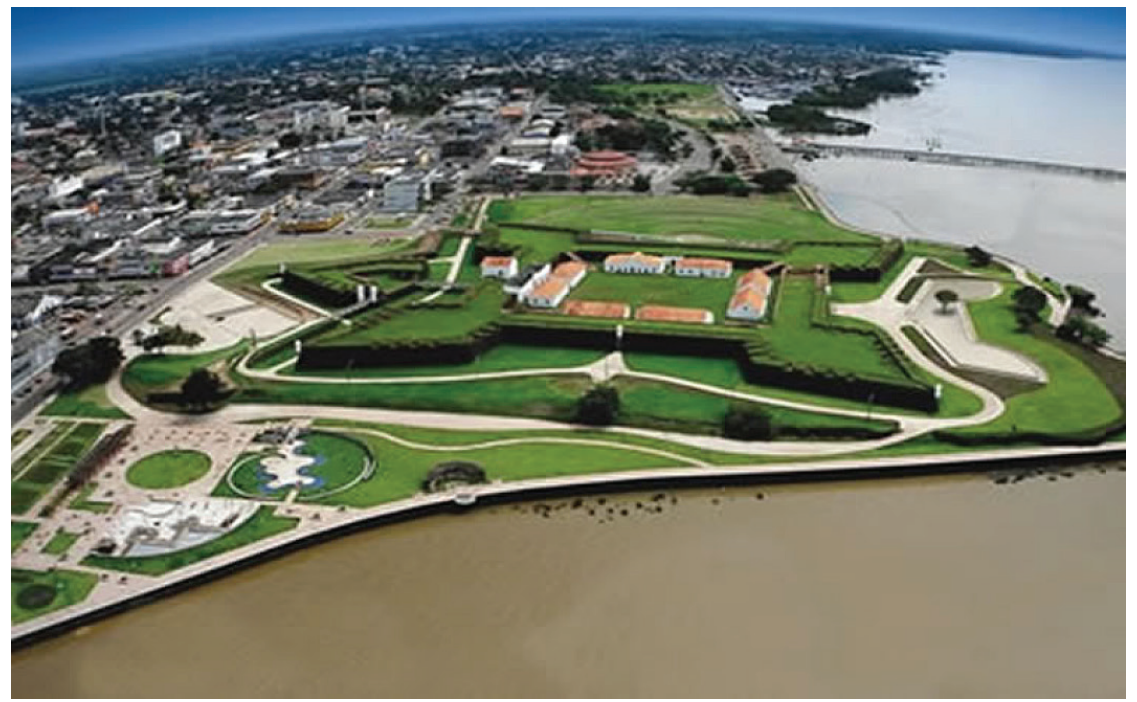

Portanto, ao lado dessa fortificação há um tempo plural, multifacetado, de mudanças e de transformações, mas também há um discurso pragmático e político, pois, como bem lembrado por Canto (2014), as transformações ocorridas nesse espaço são também dominadas por estratégias produzidas pelos sistemas políticos e por suas decisões, que reforçam as relações de poder e de dominação, bem como o esquecimento forçado dos crimes cometidos no passado.

Esquecimento, sob a perspectiva da história, é o emblema da vulnerabilidade da memória. A arte de esquecer e a outra face, que é a arte de rememorar, juntas, vão ao encontro do perdão e do apaziguamento daquilo que é lembrado. Segundo Ricoeur (2007), o esquecimento é um dano à confiabilidade da memória e, portanto, a memória é, por definição, a luta contra o esquecimento. Os grupos sociais que detiveram ou detêm o poder manipulam a memória, desejando, assim, tornarem-se senhores da memória e do esquecimento (Le 
Goff, 1984). Revelar documentos e depoimentos de pessoas que sofreram as ações ditatoriais no Brasil, durante a ditadura civil-militar, significa trazer das profundezas do silêncio aquilo que se pretendia esconder e manipular.

As autoras tentaram estudar a Fortaleza de São José de Macapá como o documento que representa, ao mesmo tempo, a fria materialidade das muralhas - que são reais e estão presentes - e as vidas de homens e mulheres - que estão ausentes porque ficaram no passado - submetidas aos anos de tortura da ditadura civil-militar no Brasil. Portanto, estudar o forte de Macapá como o lugar do cárcere e tortura significa garantir, não somente aos amapaenses, mas a todos os brasileiros, o conhecimento do passado que não queremos mais esconder, porque compreendemos que nesse processo de lembrar há um pleno exercício de cidadania.

Na confrontação entre memória e esquecimento, lembrar significa não repetir os erros do passado. A Fortaleza de São José de Macapá, como patrimônio tombado pelo Iphan é, atualmente, espaço museológico e, portanto, tem função educativa. Assim, como patrimônio cultural, material ou imaterial, pode ser instrumento representativo das memórias, das identidades e da diversidade cultural. Com isso, o conhecimento ganha um importante aliado na recuperação das ações das personagens silenciadas pela história oficial que, no caso do forte de Macapá, dizem respeito à história de homens e de mulheres que, em diferentes momentos, participaram de grandes transformações sociais, culturais e políticas em território amapaense. ${ }^{20}$

Patrimônio é memória. Portanto, os bens culturais não são apenas registros que ficaram no passado, mas podem e devem ser instrumentos de construção e de reconstrução do presente "que se atualiza[m] constantemente com as identidades e as interpretações da cidade, e ante as ações daqueles que vivem e convivem na sociedade" (Pinheiro, 2015, p. 13). Por isso são tão necessários estudos acadêmicos e projetos de educação patrimonial que analisem a função da FSJM como lugar de cárcere político da ditadura civil-militar no Brasil,

\footnotetext{
${ }^{20}$ Recentemente o Iphan criou a categoria “Conjunto de fortificações do Brasil”. Nela, a Fortaleza de São José de Macapá está inscrita com mais 18 fortificações identificadas em dez estados brasileiros. Para mais detalhes ver Iphan. Conjunto de fortificações do Brasil. (Disponível em: <http://portal.jphan.gov.br/pagina/detalhes/821: :text=0\%2Oconjunto\%20de\%20 fortifica\%C3\%A7\%C3\%B5es\%2Oimplantado,diferenciado\%2Odas\%2Ooutras\%2Opot\%C3\%AAncias\%2Ocoloniais>. Acesso em: 27 ago. 2020). As fortificações que integram a categoria "Fortificações do Brasil" também estão inscritas na Lista Indicativa a Patrimônio Mundial da Unesco. A relevância desse conjunto de fortificações está na observação das características dos traçados arquitetônicos vindos de diferentes lugares da Europa e baseia-se na fase das construções que remetem ao período colonial. A candidatura a Patrimônio Mundial encontra-se em fase de preparação e foi o tema da "Carta do Recife", assinada durante o Seminário Internacional Fortificações Brasileiras, realizado em abril de 2017, em Recife-PE (Iphan. Fortificações brasileiras. Disponível em: http://portal.jphan.gov.br/pagina/detalhes/1609. Acesso em: 27 ago. 2020).
} 
visto que esse capítulo lamentável da história recente do país, que ocorreu do lado de dentro das muralhas da fortaleza, ainda necessita ser reconhecido.

Mesmo que essa representação de ícone de medo e terror da ditadura atribuída ao forte de Macapá seja algo circunscrito à memória das pessoas que vivenciaram o regime ditatorial ou tiveram parentes que foram vítimas deste, o trabalho de investigação realizado pela Comissão Estadual da Verdade do Amapá, através dos testemunhos, identifica a Fortaleza de São José de Macapá como principal local de prisões e de torturas do período em questão em território amapaense.

As autoras compreendem que somente através de um amplo movimento de reconstrução histórica, seja através de pesquisas, eventos e publicações, seja por meio da adoção de medidas e de políticas públicas voltadas para a busca da verdade, da reparação, da garantia de direitos e da prevenção de novas violações, será possível o reconhecimento social e político desses espaços como lugares de memória da ditadura brasileira, para que isso nunca mais aconteça.

\section{Referências}

AMAPÁ. Relatório final da Comissão Estadual da Verdade do Amapá. Macapá: Secom, 2017.

ARAÚJO, Maria Paula. O ensino da ditadura militar nas escolas: problemas e propostas de trabalho. In: ARAÚJO, Maria Paula; SILVA, Izabel Pimentel da; SANTOS, Desirree dos Reis. Ditadura militare democracia no Brasil: história, imagem e testemunho. Rio de Janeiro: Ponteio, 2013, p. 10-11.

BAUER, Caroline Silveira. Como será o passado: história, historiadores e a Comissão Nacional da Verdade. São Paulo: Paco, 2017.

BAUER, Caroline Silveira. Posfácio: democracia, ditadura, tempo presente. In: DAHÁS, Nashia; RIBERT, Larissa; JOFFILY, Mariana (orgs.). 1968: perspectiva desde o tempo presente. São Paulo: Letra e Voz, 2020, p. 227-233.

BRASIL. Relatório da Comissão Nacional da Verdade, v. I. Brasília: CNV, 2014.

BRASIL. Anuário brasileiro de segurança pública, 2019. São Paulo: Fórum Brasileiro de Segurança Pública, ano 13, 2019. Disponível em: https://forumseguranca.org.br/ anuario-brasileiro-seguranca-publica. Acesso em: 10 ago. 2020.
CALIL, Gilberto Grassi. Elio e a ditadura brasileira: uma interpretação revisionista. In: JÚNIOR SENA, Carlos Zacarias de; MELO, Demian Bezerra de; CALIL, Gilberto Grassi (orgs.). Contribuição à historiografia revisionista. Rio de Janeiro: Consequência, 2017, p. 79-112.

CANTO, Fernando. Vertentes discursivas da Fortaleza de São José de Macapá: das cartas dos construtores às transformações e apropriações simbólicas contemporâneas. Macapá: Editora da Unifap, 2014.

CANTO, Fernando. Depoimento de 2 de setembro de 2016. Acervo CEV-AP (Centro de Memória, Documentação Histórica e Arquivo da Universidade Federal do Amapá, Macapá). 2 set. 2016.

CANTO, Fernando; SILVA, Isabelle da. Literatura e memória: a Fortaleza de São José de Macapá no contexto da ditadura militar em Macapá (1964-1973). Revista de Ciências Sociais (Fortaleza). v. 49, n. 2, p. 299341, 2018.

CAPIBERIBE, Camilo. Discurso proferido na audiência pública do casal João e Janete Capiberibe, 28 de março de 2014. Vídeo. Acervo CEV-AP (Centro de Memória, Documentação Histórica e Arquivo da Universidade Federal do Amapá, Macapá). 28 mar. 2014. 
CAPIBERIBE, João. Floresta do meu exílio. São Paulo: Terceiro Nome, 2013.

CAPIBERIBE, João Rodrigues. Depoimento de 21 de março de 2014. Acervo CEV-AP (Centro de Memória, Documentação Histórica e Arquivo da Universidade Federal do Amapá, Macapá). 21 mar. 2014.

CARDOSO, Josias Nogueira Hagem. Depoimento de 16 de setembro de 2014. Acervo CEV-AP (Centro de Memória, Documentação Histórica e Arquivo da Universidade Federal do Amapá, Macapá). 16 set. 2014.

CARDOSO NETO, João Francisco. Depoimento de 24 de novembro de 2014. Acervo CEV-AP (Centro de Memória, Documentação Histórica e Arquivo da Universidade Federal do Amapá, Macapá). 24 nov. 2014.

GAGNEBIN, Jeanne Marie. O preço de uma reconciliação extorquida. In: TELES, Edson; SAFATLE, Vladimir (orgs.). O que resta da ditadura. São Paulo: Boitempo, 2010, p. 177-186.

GODINHO, Ruy. Então foi assim: os bastidores da criação musical brasileira: amapaenses. Macapá: Fundação Municipal de Cultura, 2019.

HOFFMAN, Felipe; FROTA, Maria Guiomar. Museus e justiça de transição no contexto brasileiro: memória e informação na construção de espaços de representação do trauma. Em Questão (Porto Alegre). v. 25, n. 2, p. 278-299, 2019.

LE GOFF, Jacques. Documento/Monumento. In: RUGGIERO, Romano (dir.). Enciclopédia Einaudi. Lisboa: Imprensa Nacional/Casa da Moeda, v. 1, 1984. p. 95 106.

NASCIMENTO, Cláudio. Depoimento de 28 de agosto de 2014. Acervo CEV-AP (Centro de Memória, Documentação Histórica e Arquivo da Universidade Federal do Amapá, Macapá). 28 ago. 2014.

NORA, Pierre. Entre memória e história: a problemática dos lugares. Projeto História (São Paulo). n.10, p. 7-28, dez. 1993.

OLIVEIRA, Adamor de Sousa Oliveira. Tesouros de memória. Fortaleza: Premius, 2013.

P., J. L. Depoimento de 12 de novembro de 2014. Acervo CEV-AP (Centro de Memória, Documentação Histórica e Arquivo da Universidade Federal do Amapá, Macapá). 12 nov. 2014.

PENNAFORT, Hélio. 'Na falta dos autênticos, qualquer um servia pra comunista'. Jornal do Dia, p. A4, 16 nov. 1997.

PEREIRA, Raimundo Tupã dos Santos. Depoimento de 17 de março de 2013. Acervo CEV-AP (Centro de Memória, Documentação Histórica e Arquivo da Universidade Federal do Amapá, Macapá). 17 mar. 2013.

PINHEIRO, Adson Rodrigues S. (org.) Cadernos do Patrimônio Cultural: educação patrimonial. v.l. Fortaleza: Secultfor/Iphan, 2015.

POLLAK, Michel. Memória, esquecimento e silêncio. Estudos Históricos (Rio de Janeiro). v.2, n.3, p. 3-15, 1989.

RICOEUR, Paul. A memória, a história, o esquecimento. Tradução Alain François et al. Campinas: Editora da Unicamp, 2007.

SANTOS, Dorival da Costa dos. O regime ditatorial militar no Amapá: terror, resistência e subordinação, 1964-1974. Dissertação (Mestrado em História), Universidade de Campinas. Campinas, 2001.

SELIGMANN-SILVA, Márcio. O testemunho: entre a ficção e o 'real'. In: SELIGMANN-SILVA, Márcio (org.). História, memória e literatura: o testemunho na era das catástrofes. Campinas: Editora Unicamp, 2003, p. 371-385.

SILVA, Maura Leal da. O território imaginado: Amapá, de território à autonomia política, 1943-1988. Tese (Doutorado em História), Universidade de Brasília. Brasília, 2017.

TELES, Edson. O abismo na história: ensaio sobre o Brasil em tempos de Comissão da Verdade. São Paulo: Alameda, 2018.

TENAGLIA, Mônica; RODRIGUES, Georgete Medleg. As recomendações das comissões da verdade no Brasil sobre os arquivos da ditadura militar (19641985): uma análise dos relatórios finais. Em Questão (Porto Alegre). v. 24, n. 2, p. 280-299, 2018.

TOSI, Giuseppe et al. (org.). Justiça de transição: direito à justiça, à memória eà verdade. João Pessoa: Editora da UFPB, 2014. 